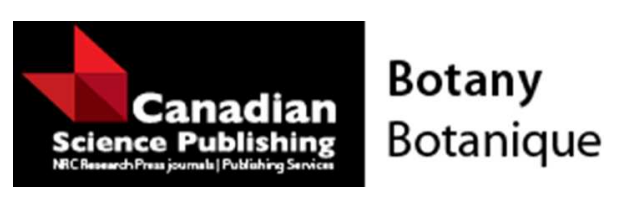

\title{
No selection for greater size in an introduced grass invading semi-arid grassland
}

\begin{tabular}{|r|l|}
\hline Journal: & Botany \\
\hline Manuscript ID & cjb-2015-0256.R1 \\
\hline Manuscript Type: & Article \\
\hline Date Submitted by the Author: & 10 -May-2016 \\
\hline Complete List of Authors: & $\begin{array}{l}\text { Hansen, Malin; University of Regina } \\
\text { Wilson, Scott; University of Regina }\end{array}$ \\
\hline Keyword: & competitive ability, plantation, Agropyron cristatum, evolution, competition \\
\hline
\end{tabular}

\section{SCHOLARONE ${ }^{\text {Th }}$ \\ Manuscripts}


No selection for greater size in an introduced grass invading semi-arid grassland

Running title: Invasion and selection

Malin J. Hansen and Scott D. Wilson

M. J. Hansen and S. D. Wilson. Department of Biology, University of Regina, Regina, Saskatchewan, S4S 0A2, Canada.

Corresponding author: Scott D. Wilson (e-mail: scott.wilson@uregina.ca) 
Invasion and selection - 2

\begin{abstract}
Exotic species are often planted for restoration or in order to enhance production. Populations that expand from plantings may undergo selection in directions that differ from those produced by artificial selection prior to planting. Here we test whether a highly productive grass, Agropyron cristatum, introduced to the semiarid Great Plains of North America, evolves during invasion from seeded fields into native grassland. We grew individuals of Agropyron cristatum from six seeded populations and twelve invading populations in twelve common gardens separated by 0.5 -- $12 \mathrm{~km}$ for two growing seasons. Contrary to expectations, individuals from invading populations did not have significantly greater tiller number or growth (increase in tiller number) than did individuals from seeded populations, suggesting that they have not undergone evolution towards increased invasion ability through increased size or growth. Instead, there was a general trend for individuals from invading populations to have lower growth rates and fewer tillers when grown without neighbours. Large size or high growth rates arising from artificial selection prior to introduction may be disadvantageous to populations invading semiarid grassland on dry, nutrient-poor soils. In this case evolution may have resulted in convergence between the relatively large planted species and the smaller native species.
\end{abstract}

Keywords: Agropyron cristatum, biomass, competition, competitive ability, evolution, plantation, tiller number 


\section{Introduction}

Invasions are well-suited to the study of rapid natural selection (Hastings et al. 2005; Sax et al. 2007; Westley 2011), and natural selection during invasion may contribute to continuing invader success (Perkins et al. 2013). Much of our knowledge about evolution in invasive species comes from comparisons of populations from home and invaded ranges (Leger and Rice 2003; Maron et al. 2004; Buswell et al. 2011). Evolution in invasive plants has also been studied in species that spread from plantations into adjacent habitats (Reichard and White 2001; Larcombe et al. 2013; Hui et al. 2014), because deliberately introduced species have rates of naturalization about three-fold greater than that of all invasive species considered together (Williamson and Fitter 1996). Deliberately introduced species have likely undergone artificial selection before introduction for traits associated with invasiveness, such as high seed production and establishment ability (Gurevitch et al. 2011; Driscoll et al. 2014). Cases involving contrasting environments on two sides of a human-created ecotone, such as mine spoils or plantations, are thought to be especially strong candidates for finding evidence of rapid selection (Linhart and Grant 1996). Here we test whether a widespread, deliberately introduced species has undergone natural selection during invasion from seeded stands into adjacent native vegetation. We examine three traits widely thought to contribute to invasive ability: growth rate, size, and the ability to compete with neighbours.

Case studies often show that individuals of invasive species are faster-growing or larger in invading populations than those of non-invasive species (Blumenthal and Hufbauer 2007; Barney et al. 2009; Matesanz and Sultan 2013). On the other hand, reviews that consider several studies or multiple species tend to find fewer differences in growth rate or size between invading and non-invading populations (Willis et al. 2000; Maron et al. 2004; Müller and Martens 2005). 
Invasion and selection - 4

Whether selection occurs for greater size may depend on the environment being invaded (Hierro et al. 2009). Large size and high growth rates may be most advantageous, and enhance competitive ability, in disturbed habitats with enhanced establishment opportunities and increased availability of resources such as light, nutrients or water (Matesanz and Sultan 2013). On the other hand, small size and low growth rates may be advantageous and enhance competitive ability in undisturbed, constantly occupied environments, such as perennial semiarid grasslands, where resource availability is low, and traits such as high nutrient use efficiency, or high root: shoot ratios, contribute to success (Aarssen et al. 2006; Scheiter and Higgins 2007; Lamb and Cahill 2008). A review of 26 invasive plant species found some examples of increased size following invasion but no examples of decreased size (Parker et al. 2013). In contrast, a herbarium survey of naturalized plants in Australia found a trend for decreasing size with time (Buswell et al. 2011). Similarly, individuals of the grass Elymus elymoides introduced for restoration in arid Nevada have undergone evolution for reduced size relative to the source population (Kulpa and Leger 2013). In total, there is evidence for both increased and decreased size in invasive species.

Another trait that may undergo selection during invasion is competitive ability (Blossey and Nötzold 1995; Leger 2008), which may (Grime 1977) or may not (Tilman 1988) be related to large size and high growth rate. Of all the factors limiting invasion, competition is among those most reliably present (Uriarte et al. 2002; Vila and Weiner 2004; Pellock et al. 2013), so an ability to grow in the presence of native neighbours, i.e., an enhanced competitive response (Goldberg 1997), might be selected for in invasive populations. As for size and growth rates, experimental results are mixed (Blair and Wolfe 2004; Zou et al. 2008). In contrast to evolution for enhanced competitive ability, if a species invades away from a plantation of conspecifics 
with identical niches, and into a community dominated by other species with different niches, there may be less intense competititon and reduced selection for competitive ability (Uriarte et al. 2002; Bossdorf et al. 2004; Gurevitch et al. 2011).

We studied a widely-introduced species, Agropyron cristatum (crested wheatgrass, hereafter called Agropyron), that readily invades and reduces diversity in native grassland (Heidinga and Wilson 2002; Henderson and Naeth 2005; Hansen and Wilson 2006) and is included in the U. S. Invasive Plant Atlas (http://www.invasiveplantatlas.org/grass.html). Agropyron is an outcrossing (Stebbins 1957), perennial $\mathrm{C}_{3}$ tussock grass that is widely seeded for forage and soil stabilization, and was present on 15-26 million ha in North America by the 1980s (Lesica and DeLuca 1996) in persistent stands characterized by low diversity (Marlette and Anderson 1986; MacDougall et al. 2008). Stands of Agropyron have roughly double the root length and 50\% greater shoot mass than native grassland (Balogianni et al. 2014; Vaness et al. 2014). Artificial selection of Agropyron cultivars for high production began in 1917 in North America, using seeds from Russian research farms, from populations that had presumably also undergone artificial selection (Knowles 1955; Asay et al. 1992).

A rigorous method for testing whether evolution accompanies invasion is the use of common garden experiments, because growing different genotypes in controlled conditions eliminates other possible sources of differences such as plasticity or environment (Gray 1986; Kawecki and Ebert 2004; Maron et al. 2004). We used common gardens in the field to test the hypotheses that seeded and invading populations of Agropyron differ in their growth rates, size and competitive abilities.

\section{Materials and methods}


Invasion and selection - 6

We worked in Grasslands National Park $\left(49^{\circ} 22^{\prime} \mathrm{N}, 107^{\circ} 53^{\prime} \mathrm{W}\right)$ near Val Marie in southwestern Saskatchewan, Canada. Native vegetation is dominated by Bouteloua gracilis (blue grama grass), Stipa comata (needle-and-thread grass) and Selaginella densa (spikemoss). In the early 1900s many areas were cultivated but abandoned several decades later, with abandoned areas either reverting to native grassland or being seeded with Agropyron. Today, the region is a matrix of formerly cultivated grasslands and smaller remnants of uncultivated prairie (Christian and Wilson 1999). Fields seeded with Agropyron are sources of invasion into adjacent native grassland (Heidinga and Wilson 2002; Henderson and Naeth 2005). The study area has not been grazed by cattle in several decades but grazing by rodents, deer and pronghorn may have occurred.

We tested for differences in growth rate, size and competitive ability among three populations of Agropyron: 1) populations seeded in old fields ("seeded populations"); 2) invading populations in native grassland $50( \pm 10)$ m outside of a seeded field ("50-m populations"); and 3) invading populations in native grassland $100( \pm 10)$ m outside of a seeded field ("100-m populations"). For brevity, we refer to these groups as "populations" although we cannot rule out interbreeding among them.

Our seeded populations of Agropyron were planted during 1945 - 1955 when agricultural fields were retired from cultivation (Christian and Wilson 1999). As these are long-lived perennials, the seeds collected in 2003 from seeded populations came either from originallyseeded genotypes or from their descendents that had grown in a neighbourhood that was still dominated by Agropyron. Agropyron readily invades native grassland from seeded stands (Pyke 1990; Larson et al. 2001). In our region, Agropyron cover in native grassland decreases significantly with distance from seeded fields (Heidinga and Wilson 2002). Agropyron has 
invaded about $200 \mathrm{~m}$ into native grassland over 50 years (Hansen 2006). Invading tussocks are isolated from one another, and the lack of rhizomes in this species indicates that invasion results from seed dispersal. We assume that seeds collected from invading populations in 2003 came either from original invaders that dispersed into native grassland from seeded fields, or from their descendents that had grown in neighbourhoods dominated by native species (Christian and Wilson 1999). We studied populations $50 \mathrm{~m}$ and $100 \mathrm{~m}$ from the edge in order to increase the generality of the results and to test for possible differences associated with distance from the seeded populations.

Seeds were collected at six sites separated by $0.5-12 \mathrm{~km}$ (Fig. 1), in order to increase the generality of the results. Sites had similar elevations, soil types, disturbance regimes and vegetation. Seeds were collected from at least 100 individuals in each population at each site in fall 2003. Seeds were stored frozen (to simulate winter) until being seeded individually in March 2004 in pots $(2.5 \mathrm{~cm}$ diameter, $12 \mathrm{~cm}$ deep) containing a 2:1 mixture of peat and potting soil. Pots were watered to field capacity daily, but received no supplemental light or fertilizer, in a greenhouse about $300 \mathrm{~km}$ from the study site.

Seedlings were transplanted into common gardens at each of the six sites, with each population in its respective home site. In order to enhance the generality of the study, we duplicated each common garden in two vegetation types at each site: in native grassland and in an old field formerly cultivated and subsequently seeded with Agropyron c. 60 year ago (Christian and Wilson 1999). Gardens at each site were c. $100 \mathrm{~m}$ apart. Seedlings were transplanted in early June 2004 (after the last frost) and grown for two growing seasons. Transplants were grown individually in polyvinylchloride tubes $(10 \mathrm{~cm}$ diameter, $15 \mathrm{~cm}$ deep), inserted $11 \mathrm{~cm}$ into the ground. The $4 \mathrm{~cm}$ remaining above the ground retained water added to 
Invasion and selection - 8

enhance early seedling survival. Tubes were necessary to decrease competition from neighbor roots, which is intense in these environments, and this size of tube does not appear to constrain grass transplant growth in our region (Peltzer and Wilson 2001).

We transplanted one seedling in the center of each tube by inserting the entire soil core from the pot into the ground after removing a soil core of the same size. To facilitate establishment, all transplants were shaded during the first growing season using vertical opaque plastic sheets (20 cm wide, $40 \mathrm{~cm}$ tall) $10 \mathrm{~cm}$ southwest of each transplant (Peltzer and Wilson 2001) and supplied with $30 \mathrm{~mm}$ of water every two weeks during the field season in 2004, but not in 2005. This may have reduced competition for water in 2004 but was necessary to allow transplant establishment by reducing transplant shock. Grazed, damaged, or dead transplants were replaced for up to two weeks after planting.

In order to test for differences among populations in competitive ability, transplants in each common garden were grown in two competition treatments: neighbours present and no neighbours present (Peltzer and Wilson 2001). Comparison of performance in these treatments measured the ability of plants to grow in the presence of neighbours, sometimes defined as competitive response (Goldberg 1997). Half the tubes were assigned to each competition treatment. Vegetation in tubes with neighbours present was undisturbed, and live roots and shoots of neighbours persist within tubes of this size in our region (Bakker and Wilson 2001). Vegetation in tubes assigned to the no-neighbour treatment was sprayed with a $1 \%$ solution of the nonselective herbicide glyphosate (Roundup, Monsanto, St. Louis, MO) two weeks before seedlings were transplanted. Glyphosate decomposes in the soil into non-active compounds (Grossbard and Atkinson 1985). Neighbour shoot regrowth inside no-neighbour tubes was subsequently removed by hand. 
Each common garden comprised six parallel rows of tubes. Rows were separated by 10 $\mathrm{m}$, and tubes within each row were separated by $5 \mathrm{~m}$. One of each of the six treatment combinations (three populations in each of two competition treatments) were randomly assigned to one of the six rows, with ten replicate tubes in each row. Treatments were arranged in rows in order to facilitate experiment installation and maintenance, and the use of six widely dispersed sites caused the treatments to be interspersed across the $50 \mathrm{~km}^{2}$ of the study area. Thus, the experiment comprised six sites, each containing three populations, two competition treatments, and 10 replicates. In total, 720 seedlings were transplanted (six sites $\mathrm{x}$ three populations $\mathrm{x}$ two competition treatments $\mathrm{x} 10$ replicates $\mathrm{x}$ two vegetation types).

Tillers of transplants were counted at the time of transplanting (June 2004) and in late August of 2005. Tiller (a stem and associated leaves, flowers and roots) number provides a nondestructive measure of initial size and growth. Relative growth in tiller number (hereafter "tiller growth") was determined for each transplant as ((tiller number in August 2005 - tiller number in June 2004)/tiller number in June 2004). Both tiller number and growth were examined because growth takes into account variation in initial size. Transplants were harvested (cut just above the roots) in late August 2005. Roots were not harvested to minimize disturbance to the study site, a national park. Root: shoot ratios vary among environments and competition treatments in grassland neighbour-removal experiments, but not enough to influence the interpretation of the results based on shoot mass alone (Peltzer et al. 1998). Harvested above-ground biomass of transplants was dried to constant mass and weighed.

Variation in tiller growth, final tiller number, and shoot mass among the three populations and two competition treatments were examined using analysis of variance (ANOVA) with population, competition, and vegetation type nested within site. Because 
vegetation type had no effect on any dependent variable, we also conducted ANOVA with population and competition nested within site (i.e. with vegetation type pooled); this analysis produced results similar to the first and we do not report them here. Lastly, we analysed the results for each vegetation type separately in order to avoid variation introduced by including different vegetation types. Data were log-transformed to reduce heterogeneity. Analyses were performed using JMP (SAS Institute, Cary, NC). A significant population effect would indicate that selection had occurred to differentiate the three populations. A significant interaction between population and competition would indicate that the three populations had different competitive responses. We also calculated the competitive response for each population in each vegetation type as relative interaction intensity (Armas et al. 2004) and tested whether this varied among populations.

\section{Results}

\section{Old-field gardens}

Vegetation type had no effect on any aspect of transplant performance $\left(\mathrm{F}_{6,518}=0.50-\right.$ 0.77, $\mathrm{P}>0.05)$. In an ANOVA of common gardens in old-fields, tiller growth and final tiller number varied significantly $(P<0.05)$ among populations (Fig. 2, Table 1). Shoot mass did not vary significantly among populations (Table 1).

A significant interaction between population and competition occurred for both tiller growth and number (Table 1), with two implications. First, the interaction suggests that differences among populations occurred only in some competition treatments. Pairwise comparisons showed that 50-m populations produced significantly fewer new tillers than did 
seeded populations, but only when grown with all neighbours present (Fig. 2a). In contrast, 100m populations were intermediate between seeded and 50-m populations. For tiller number, we detected no significant differences among populations grown with all neighbours present, probably due to reduced degrees of freedom for the pairwise comparisons relative to the complete ANOVA. Thus, one aspect of the significant interaction between population and competition is that differences among populations were detected only in the presence of neighbours. Second, the interaction suggests that populations varied in the way they responded to the presence of neighbours. Neighbours significantly decreased tiller growth and tiller number for 50-m populations (Fig. 2a and b) but had no significant effect in other cases. Thus, only individuals from the 50-m populations were significantly suppressed by competition. Shoot mass did not vary with the interaction between population and competition but was significantly lower in the presence of neighbours (Fig. 2c, Table 1). Tiller growth and number varied significantly among the six sites (Table 1), reflecting a 2-3-fold variation among sites (data not shown). Shoot mass did not vary significantly among sites (Table 1).

\section{Native-grassland gardens}

For common gardens in native grasslands, no response variable differed significantly among populations (Table 1, Fig. 3). Similarly, no response varied significantly with the interaction between population and competition. In summary, we found no evidence of differences among populations in size, growth or competitive ability for transplants growing in native grassland. Tiller growth, number and shoot mass varied significantly between competition treatments (Fig. 3, Table 1), suggesting that competition limited growth for all populations. Tiller growth and number varied significantly among the six sites (Table 1), whereas shoot mass did not. 
Invasion and selection - 12

\section{Competitive response}

Competitive response, calculated as relative interaction intensity, did not vary significantly among populations for any response variable $\left(F_{2,30}=0.003-0.038, P>0.05\right)$.

\section{Discussion}

Individuals of invading populations of Agropyron were never larger than those of seeded populations. In only one case out of six examined (three variables and two vegetation types), tiller growth was significantly lower in one invading population than in seeded populations (Fig. 2a, 50-m population). On the other hand, the trend for slower growth and smaller size was consistent for all variables in both vegetation types for plants grown singly.

Our results contrast with many findings of increased size in invasive populations (Blumenthal and Hufbauer 2007; Zou et al. 2008; Barney et al. 2009) but are consistent with findings of no difference in size (Maron et al. 2004; Müller and Martens 2005; Parker et al. 2013). Further, a survey showed a decrease in size of invading populations (Buswell et al. 2011). This variation suggests that the direction of evolution of size in invasive populations is contextdependent, varying with both the habitat undergoing invasion (in terms of nutrient, water and neighbour abundance) and the origin of the invasive species (previously having undergone artificial selection or not).

The absence of higher growth rates in individuals from invading than from seeded Agropyron populations may be related to the agricultural reasons for its introduction. High growth rates, along with frequent establishment and high production, are among the characters selected for in species that have been introduced to improve stand productivity (Gaskin and 
Schaal 2002; Gurevitch et al. 2011; Driscoll et al. 2014), such as Agropyron (Harris and Dobrowolski 1986; Lesica and Atthowe 2007), Medicago, Trifolium (Schweitzer et al. 1993), Populus (McIntyre and Whitham 2003), Eucalytus and Pinus (Richardson 1998). High growth rates, however, might be a disadvantage in invaded natural environments such as semiarid grasslands, which are characterized by high evaporation, low rainfall, dry soils, low rates of nutrient cycling, and low soil nutrient availability, and are naturally dominated by plants with relatively low growth rates (Gibson 2009). Further, intense belowground competition (Fowler 1986; Wilson and Tilman 1995) in native grassland may select for high allocation to roots rather than shoots (Wedin and Tilman 1993), which may result in slow tiller production in individuals of invading populations. In addition, large genotypes are more likely than small ones to be grazed and selected against, especially in the case of an invasive species that has greater stature than the invaded community (Bagchi and Ritchie 2010), as is the case for Agropyron. Species invading native vegetation may experience rapid natural selection for traits that confer fitness in the new environment (Linhart and Grant 1996), but these traits are not necessarily equivalent to enhanced stature or growth rate (Bossdorf et al. 2004; Maron et al. 2004; Lambdon 2008). Similar to our results, the majority of naturalized species in arid Australian habitats became shorter over time (Buswell et al. 2011) and individuals that established in arid grassland restorations were genotypically smaller than those in the source population (Kulpa and Leger 2013). In practical terms, evolution towards smaller size raises the possibility that the long-term outcome of invasion may be co-existence with the native species already present (Wilson and Pärtel 2003), and a limited loss of diversity.

Differences in competitive ability among populations were suggested by significant interaction terms between population and competition but only for tiller growth and number in 
Invasion and selection - 14

old-field gardens (Table 1). Comparisons of competition treatments for each population show that the 50-m populations were significantly suppressed by neighbours when grown in old fields, but that seeded populations and 100-m populations were not (Fig. 2a and b). The susceptibility of only the 50-m populations to competitive suppression is surprising since they should have undergone evolution for resisting competitive suppression from intraspecific neighbours longer than populations in seeded fields or those in the $100-\mathrm{m}$ populations. On the other hand, there may be no linear relationship between population age and distance from the planted field if establishment is dependent on stochastic establishment or dispersal events.

In contrast to transplants grown in old-field common gardens (Fig. 2) where tiller growth and number varied significantly among populations, transplants in native grassland gardens showed no differences among populations (Fig. 3). One possible reason for this is that amongpopulation differences in Agropyron emerged only where transplants were grown among conspecific Agropyron neighbours in old fields, either because of plant-soil feedbacks (Bever et al. 2010; Perkins and Nowak 2012) or due to relatively strong intraspecific competition (Uriarte et al. 2002; Bossdorf et al. 2004). On the other hand, the detection of evolution also varied among sites in a large-scale, multiple garden experiment in California (Leger and Rice 2003), suggesting that the manifestation of evolution depends on environment. Further, populationcompetition interactions were not found in the native grasslands (Table 1). Thus, there was no evidence that evolution resulted in enhanced competitive ability in invading populations, in accordance with other experimental tests of invasion-related evolution for enhanced competitive ability (Blair and Wolfe 2004; Franks et al. 2008; Leger 2008). The lack of consistent differences in competitive ability among populations in native grasslands may be related to our measure of competitive ability, which was competitive response (Goldberg and Landa 1991), the ability of a 
plant to grow in the presence of neighbours. We grew plants in the field, with low water and nutrient availability, in soil filled with neighbour roots (Vaness et al. 2014). Some studies that explore competitive ability comprise pot experiments in which seedlings grow in initially rootfree, relatively nutrient-rich, well-watered soil (Zou et al. 2008; Matesanz and Sultan 2013; Sun et al. 2013). The suppression of transplants in field experiments on nutrient-poor, root-filled dry soil for a year after supplemental watering ceased may not be comparable to those from seedlings grown in pairwise combinations in containers in more benign conditions. Further, evolution for enhanced competitive ability has been proposed to occur primarily in response to a lack of herbivores in the invaded range (Blossey and Nötzold 1995; Siemann and Rogers 2001; Franks et al. 2008). In the case of Agropyron, however, there may be small or no differences in herbivores between seeded fields and nearby invading populations, and thus no herbivore-driven evolution for enhanced competitive ability.

A lack of evolution for competitive ability may also arise from several factors that work against evolution in general (Kawecki and Ebert 2004). First, gene flow from more dense (seeded fields) to less dense (invading) populations in the normally outcrossing Agropyron may counteract evolution (Lenormand 2002; Rice and Knapp 2008). Second, selection is most likely to occur under conditions that allow rapid population growth, producing more offspring and generations to undergo selection (Reznick and Ghalambor 2001), but the growth of Agropyron populations in the presence of neighbours is relatively slow (Hansen and Wilson 2006). Temporal environmental variability may prevent strong selection for local adaptation (Kawecki and Ebert 2004), and semarid grasslands have relatively large among-year variability in productivity (Smith et al. 2009). Lastly, phenotypic plasticity allows populations to cope with environmental variation without evolution (Willis et al. 2000), and many agricultural cultivars, 
Invasion and selection - 16

invasive hybrids, and weeds possess high phenotypic plasticity (Neuffer et al. 1999; Gaskin and Schaal 2002; Parker et al. 2003). Plasticity in their response to the presence of neighbours might prevent some invading plant populations from being selected for high competitive response ability.

We found significant differences among populations in old-field gardens but not in nearby grassland gardens (Table 1). A different analysis of the two habitats together, with vegetation as a main effect, showed no significant differences between old fields and grasslands, as reflected by the similar ranges in the $y$-axes in Figures 2 and 3. The lack of differences may reflect the arbitrary nature of the original old-field boundaries, because fields were allotted by legal description. Further, there may be pre-existing differences in the abiotic environment between old fields and adjacent natural grassland (Christian and Wilson 1999). Lastly, the seeded populations may represent different cultivars of Agropyron (Asay et al. 1992). Far stronger than the effects of population was the main effect of competition, because competition consistently decreased transplant performance. Neighbour identity in native grassland almost certainly varied among the tubes in which transplants grew, but the replication of competition treatments and the use of several sites allowed us only to discuss the overall influence of neighbours without exploring species-specific effects.

The population and competition treatments were not interspersed at each site due to constraints imposed by time and resources. If the experiment had used only one site, and if we had compared a population in one row with another population in a different row, this would be a clear example of psuedoreplication (Hurlbert 1984). However, the population and competition treatments were interspersed over the whole experiment because we used six widely-spaced sites (Fig. 1). It is difficult to imagine how pre-existing environmental gradients (Hurlbert's non- 
demonic intervention) could contribute to the differences we found among populations when the results were generated from six sites scattered across c. $50 \mathrm{~km}^{2}$.

In addition to differences among populations, the experiment also revealed significant variation among study sites in tiller growth and number (Table 1). There are two possible causes for this: differences among sites in productivity caused by environment and differences among the cultivars that were seeded at the different sites. Our design does not allow the parsing of these causes, but the use of six sites increased the generality of the findings. Results with less variation would likely emerge from using fewer sites. On the other hand, using several sites allows the variable of interest to be set in the context of relevant background variation in environment and among planted genotypes. In this case, competition was the factor that most consistently influenced transplant performance. Lastly, it is possible that the inclusion of roots in our measures of transplant performance might have produced different results. On the other hand, field competition experiments give similar results regardless of whether roots are included (Peltzer et al. 1998).

In total, our field experiment found no evidence for evolution for increased size, growth, or ability to grow in the face of competition in the case of this widely introduced and invasive species. For invaders of semiarid grasslands that were introduced for agricultural purposes, low growth rates and small size may represent an open evolutionary pathway for populations that have previously undergone artificial selection for high productivity.

\section{Acknowledgements}

We thank D. Arbuthnott, D. Donald, C. Herle and K. Fink for field help, P. Fargey and A. Sturch of Grasslands National Park for logistical support, J. Bakker, A. MacDougall and 
reviewers for comments on earlier versions of the paper, and the Natural Sciences and Engineering Research Council of Canada for funding.

\section{References}

Aarssen, L.W., Schamp, B.S., and Pither, J. 2006. Why are there so many small plants? Implications for species coexistence. J. Ecol. 94: 569-580.

Armas, C., Ordiales, R.N., and Pugnaire, F.I. 2004. Measuring plant interactions: a new comparative index. Ecology 85: 2682-2686.

Asay, K.H., Jensen, K.B., Hsiao, C., and Dewey, D.R. 1992. Probable origin of standard Crested Wheatgrass, Agropyron desertorum Fisch. ex Link, Schultes. Can. J. Pl. Sci. 72: 763-772.

Bagchi, S., and Ritchie, M.E. 2010. Herbivore effects on above- and belowground plant production and soil nitrogen availability in the Trans-Himalayan shrub-steppes. Oecologia 164: 1075-1082. doi: 10.1007/s00442-010-1690-5.

Bakker, J.D., and Wilson, S.D. 2001. Competitive abilities of introduced and native grasses. Plant Ecol. 157: 119-127.

Balogianni, V.G., Wilson, S.D., Vaness, B.M., MacDougall, A.S., and Pinno, B.D. 2014. Distinct root and shoot responses to mowing and fertility in native and invaded grassland Rangeland Ecol. Manage. 67: 39-45.

Barney, J.N., Whitlow, T.H., and DiTommaso, A. 2009. Evolution of an invasive phenotype: shift to belowground dominance and enhanced competitive ability in the introduced range. Plant Ecol. 202(2): 275-284. doi: 10.1007/s11258-008-9481-3.

Bever, J.D., Dickie, I.A., Facelli, E., Facelli, J.M., Klironomos, J., Moora, M., Rillig, M.C., Stock, W.D., Tibbett, M., and Zobel, M. 2010. Rooting theories of plant community ecology in microbial interactions. Trends Ecol. Evol. 25: 468-478. 
Blossey, B., and Nötzold, R. 1995. Evolution of increased competitive ability in invasive nonindigenous plants: a hypothesis. J. Ecol. 83: 887-889.

Blumenthal, D.M., and Hufbauer, R.A. 2007. Increased plant size in exotic populations: A common-garden test with 14 invasive species. Ecology 88: 2758-2765.

Bossdorf, O., Prati, D., Auge, H., and Schmid, B. 2004. Reduced competitive ability in an invasive plant. Ecol. Letters 7: 346-353.

Buswell, J.M., Moles, A.T., and Hartley, S. 2011. Is rapid evolution common in introduced plant species? J. Ecol. 99: 214-224. doi: 10.1111/j.1365-2745.2010.01759.x.

Christian, J.M., and Wilson, S.D. 1999. Long-term ecosystem impacts of an introduced grass in the northern Great Plains. Ecology 80: 2397-2407. doi: 10.1890/00129658(1999)080[2397:1teioa]2.0.co;2.

Driscoll, D.A., Catford, J.A., Barney, J.N., Hulme, P.E., Martin, T.G., Pauchard, A., Pyšek, P., Richardson, D.M., Riley, S., and Visser, V. 2014. New pasture plants intensify invasive species risk. Proc. Natl. Acad. Sci. USA 11: 16622-16627.

Fowler, N.L. 1986. Density-dependent population regulation in a Texas grassland. Ecology 67 : $545-554$.

Franks, S.J., Pratt, P.D., Dray, F.A., and Simms, E.L. 2008. Selection on herbivory resistance and growth rate in an invasive plant. Am. Nat. 171: 678-691.

Gaskin, J.F., and Schaal, B.A. 2002. Hybrid Tamarix widespread in US invasion and undetected in native Asian range. Proc. Natl. Acad. Sci. USA 99: 11256-11259.

Gibson, D.J. 2009. Grasses and grassland ecology. Oxford University Press, Oxford.

Goldberg, D.E. 1997. Competitive ability: definitions, contingency, and correlated traits. In Plant life histories: ecological correlates and phylogenetic constraints. Edited by J. Silvertown 
Invasion and selection - 20

and M. Franco and J.L. Harper. Cambridge University Press, Cambridge.

Goldberg, D.E., and Landa, K. 1991. Competitive effect and response: hierarchies and correlated traits in the early stages of competition. J. Ecol. 79: 1013-1030.

Gray, A.J. 1986. Do invading species have definable genetic characteristics? Philosophical Transactions of the Royal Society of London. Series B, Biological Sciences 314: 655672.

Grime, J.P. 1977. Evidence for the existence of three primary strategies in plants and its relevance to ecological and evolutionary theory. Am. Nat. 111: 1169-1194.

Grossbard, E., and Atkinson, D. 1985. The herbicide glyphosate. Butterworth, London.

Gurevitch, J., Fox, G.A., Wardle, G.M., Inderjit, and Taub, D. 2011. Emergent insights from the synthesis of conceptual frameworks for biological invasions. Ecol. Letters 14: 407-418.

Hansen, M.J. 2006. Prediction and management of an invasive grass (Agropyron cristatum). Ph. D. thesis, University of Regina, Regina.

Hansen, M.J., and Wilson, S.D. 2006. Is management of an invasive grass Agropyron cristatum contingent on environment? J. Appl. Ecol. 43: 269-280.

Harris, G.A., and Dobrowolski, J.P. 1986. Population dynamics of seeded species on northeast Washington semiarid sites, 1948-1983. J. Range Manage. 34: 46-51.

Hastings, A., Cuddington, K., Davies, K.F., Dugaw, C.J., Elmendorf, S., Freestone, A., Harrison, S., Holland, M., Lambrinos, J., Malvadkar, U., Melbourne, B.A., Moore, K., Taylor, C., and Thomson, D. 2005. The spatial spread of invasions: new developments in theory and evidence. Ecol. Letters 8: 91-101. doi: 10.1111/j.1461-0248.2004.00687.x.

Heidinga, L., and Wilson, S.D. 2002. The impact of an invading alien grass (Agropyron cristatum) on species turnover in native prairie. Diversity Distrib. 8: 249-258. 
Henderson, D.C., and Naeth, M.A. 2005. Multi-scale impacts of crested wheatgrass invasion in mixed-grass prairie. Biol. Inv. 7: 639-650.

Hierro, J.L., Eren, O., Khetsuriani, L., Diaconu, A., Torok, K., Montesinos, D., Andonian, K., Kikodze, D., Janoian, L., Villarreal, D., Estanga-Mollica, M.E., and Callaway, R.M. 2009. Germination responses of an invasive species in native and non-native ranges. Oikos 118: 529-538. doi: 10.1111/j.1600-0706.2009.17283.x.

Hui, C., Richardson, D.M., Visser, V., and Wilson, J.R.U. 2014. Macroecology meets invasion ecology: performance of Australian acacias and eucalypts around the world revealed by features of their native ranges. Biol. Inv. 16: 565-576. doi: 10.1007/s10530-013-0599-4.

Hurlbert, S.H. 1984. Psuedoreplication and the design of ecological field experiments. Ecol. Monogr. 54: 187-211.

Kawecki, T.J., and Ebert, D. 2004. Conceptual issues in local adaptation. Ecol. Letters 7: 12251241.

Knowles, R.P. 1955. A study of variability in crested wheatgrass. Can. J. Bot. 33: 534-546.

Kulpa, S.M., and Leger, E.A. 2013. Strong natural selection during restoration favors an unexpected suite of plant traits. Evolutionary Applications 6: 510-523.

Lamb, E.G., and Cahill, J.F. 2008. When competition does not matter: grassland diversity and community composition. Am. Nat. 171: 777-787.

Lambdon, P.W. 2008. Is invasiveness a legacy of evolution? Phylogenetic patterns in the alien flora of Mediterranean islands. J. Ecol. 96: 46-57.

Larcombe, M.J., Silva, J.S., Vaillancourt, R.E., and Potts, B.M. 2013. Assessing the invasive potential of Eucalyptus globulus in Australia: quantification of wildling establishment from plantations. Biol. Inv. 15: 2763-2781. doi: 10.1007/s10530-013-0492-1. 
Invasion and selection - 22

Larson, D.L., Anderson, P.J., and Newton, W. 2001. Alien plant invasion in mixed-grass prairie: effects of vegetation type and anthropogenic disturbance. Ecol. Appl. 11: 128-141.

Leger, E.A. 2008. The adaptive value of remnant native plants in invaded communities: An example from the Great Basin. Ecol. Appl. 18: 1226-1235.

Leger, E.A. 2013. Annual plants change in size over a century of observations. Glob. Change Biol. 19: 2229-2239. doi: $10.1111 / \mathrm{gcb} .12208$.

Leger, E.A., and Rice, K.J. 2003. Invasive California poppies (Eschscholzia californica Cham.) grow larger than native individuals under reduced competition. Ecol. Letters 6: 257-264.

Lenormand, T. 2002. Gene flow and the limits to natural selection. Trends Ecol. Evol. 17: 183189.

Lesica, P., and Atthowe, H.E. 2007. Identifying weed-resistant bluebunch wheatgrass for restoration in western Montana. Ecol. Restor. 25: 191-198.

Lesica, P., and DeLuca, T. 1996. Long-term harmful effects of crested wheatgrass on Great Plains grassland ecosystems. J. Soil Water Cons. 51: 408-409.

Linhart, Y.B., and Grant, M.C. 1996. Evolutionary significance of local genetic differentiation in plants. Ann. Rev. Ecol. Syst. 27: 237-277.

MacDougall, A.S., Wilson, S.D., and Bakker, J.D. 2008. Climate variability alters the outcome of long-term community assembly. J. Ecol. 96: 346-354.

Marlette, G.M., and Anderson, J.E. 1986. Seed banks and propagule dispersal in crestedwheatgrass stands. J. Appl. Ecol. 23: 161-175.

Maron, J.L., Vilà, M., Bommarco, R., Elmendorf, S., and Beardsley, P. 2004. Rapid evolution of an invasive plant. Ecol. Monogr. 74: 261-280.

Matesanz, S., and Sultan, S.E. 2013. High-performance genotypes in an introduced plant: 
insights to future invasiveness. Ecology 94: 2464-2474. doi: 10.1890/12-1359.1.

McIntyre, P.J., and Whitham, T.G. 2003. Plant genotype affects long-term herbivore population dynamics and extinction: conservation implications. Ecology 84: 311-322.

Müller, C., and Martens, N. 2005. Testing predictions of the evolution of increased competitive ability hypothesis for an invasive crucifer. Evol. Ecol. 19: 533-550.

Neuffer, B., Auge, H., Mesch, H., Amarell, U., and Brandl, R. 1999. Spread of violets in polluted pine forests: morphological and molecular evidence for the ecological importance of interspecific hybridization. Molecular Ecology 8: 365-377.

Parker, I.M., Rodriguez, J., and Loik, M.E. 2003. An evolutionary approach to understanding the biology of invasions: local adaptation and general-purpose genotypes in the weed Verbascum thapsus. Conservation Biology 17: 59-72.

Parker, J.D., Torchin, M.E., Hufbauer, R.A., Lemoine, N.P., Alba, C., Blumenthal, D.M., Bossdorf, O., Byers, J.E., Dunn, A.M., Heckman, R.W., Hejda, M., Jarosik, V., Kanarek, A.R., Martin, L.B., Perkins, S.E., Pysek, P., Schierenbeck, K., Schloder, C., van Klinken, R., Vaughn, K.J., Williams, W., and Wolfe, L.M. 2013. Do invasive species perform better in their new ranges? Ecology 94: 985-994.

Pellock, S., Thompson, A., He, K.S., Mecklin, C.J., and Yang, J. 2013. Validity of Darwin's naturalization hypothesis relates to the stages of invasion. Community Ecol. 14: 172-179. doi: 10.1556/ComEc.14.2013.2.7.

Peltzer, D.A., Wilson, S.D., and Gerry, A.K. 1998. Competition intensity along a productivity gradient in a low-diversity grassland. Am. Nat. 151: 465-476.

Peltzer, D.A., and Wilson, S.D. 2001. Variation in plant responses to neighbors at local and regional scales. Am. Nat. 157: 610-625. 
Invasion and selection - 24

Perkins, L.B., and Nowak, R.S. 2012. Soil conditioning and plant-soil feedbacks affect competitive relationships between native and invasive grasses. Plant Ecol. 213(8): 13371344. doi: $10.1007 / \mathrm{s} 11258-012-0092-7$.

Perkins, T.A., Phillips, B.L., Baskett, M.L., and Hastings, A. 2013. Evolution of dispersal and life history interact to drive accelerating spread of an invasive species. Ecol. Letters 16: 1079-1087.

Pyke, D.A. 1990. Comparative demography of co-occurring introduced and native tussock grasses: persistence and potential expansion. Oecologia 82: 537-543.

Reichard, S.H., and White, P. 2001. Horticulture as a pathway of invasive plant introductions in the United States. BioSci. 51: 103-113.

Reznick, D.N., and Ghalambor, C.K. 2001. The population ecology of contemporary adaptations: what empirical studies reveal about the conditions that promote adaptive evolution. Genetica 112-113: 183-198.

Rice, K.J., and Knapp, E.E. 2008. Effects of competition and life history stage on the expression of local adaptation in two native bunchgrasses. Rest. Ecol. 16: 12-23.

Richardson, D. 1998. Forestry trees as invasive aliens. Conservation Biology 12: 18-26.

Sax, D.F., Stachowicz, J.J., Brown, J.H., Bruno, J.F., Dawson, M.N., Gaines, S.D., Grosberg, R.K., Hastings, A., Holt, R.D., Mayfield, M.M., O'Connor, I., and Rice, W.R. 2007. Ecological and evolutionary insights from species invasions. Trends Ecol. Evol. 22: 465471.

Scheiter, S., and Higgins, S.I. 2007. Partitioning of root and shoot competition and the stability of savannas. Am. Nat. 170: 587-601.

Schweitzer, S.H., Bryant, F.C., and Wester, D.B. 1993. Potential forage species for deer in the 
southern mixed prairie. J. Range Manage. 46: 70-75.

Smith, M.D., Knapp, A.K., and Collins, S.L. 2009. A framework for assessing ecosystem dynamics in response to chronic resource alterations induced by global change. Ecology 90: $3279-3289$.

Stebbins, G.L. 1957. Self fertilization and population variability in the higher plants. The American Naturalist 91: 337-354.

Sun, Y., Collins, A.R., Schafner, U., and Müller-Schärer, H. 2013. Dissecting impact of plant invaders: do invaders behave differently in the new range? Ecology 94: 2124-2130.

Tilman, D. 1988. Plant strategies and the dynamics and structure of plant communities. Princeton University Press, Princeton.

Uriarte, M., Canham, C.D., and Root, R.B. 2002. A model of simultaneous evolution of competitive ability and herbivore resistance in a perennial plant. Ecology 83: 2649-2663.

Vaness, B.M., Wilson, S.D., and MacDougall, A.S. 2014. Decreased root heterogeneity and increased root length following grassland invasion. Func. Ecol. 28: 1266-1273.

Vila, M., and Weiner, J. 2004. Are invasive plant species better competitors than native plant species? -- evidence from pair-wise experiments. Oikos 105: 229-238.

Wedin, D., and Tilman, D. 1993. Competition among grasses along a nitrogen gradient: initial conditions and mechanisms of competition. Ecol. Monogr. 63: 199-229.

Westley, P.A.H. 2011. What invasive species reveal about the rate and form of contemporary phenotypic change in nature. Am. Nat. 177: 496-509. doi: $\underline{10.1086 / 658902}$.

Williamson, M., and Fitter, A. 1996. The varying success of invaders. Ecology 77: 1661-1665. Willis, A.J., Memmott, J., and Forrester, R.I. 2000. Is there evidence for the post-invasion 
Invasion and selection - 26

evolution of increased size among invasive plant species? Ecol. Letters 3: 275-283.

Wilson, S.D., and Partel, M. 2003. Extirpation or coexistence? Management of a persistent introduced grass in a prairie restoration. Rest. Ecol. 11(4): 410-416. doi: 10.1046/j.1526100X.2003.rec0217.x.

Wilson, S.D., and Tilman, D. 1995. Competitive responses of eight old-field plant species in four environments. Ecology 76: 1169-1180.

Wolfe, L.M., Elzinga, J.A., and Biere, A. 2004. Increased susceptibility to enemies following introduction in the invasive plant Silene latifolia. Ecol. Letters 7: 813-820. doi: 10.1111/j.1461-0248.2004.00649.x.

Zou, J., Rogers, W.E., and Siemann, E. 2008. Increased competitive ability and herbivory tolerance in the invasive plant Sapium sebiferum. Biol. Inv. 10: 291-302. 
Table 1. $F$-values from analyses of variance with population, competition and their interaction, nested within site. Separate analyses were conducted for experiments in old-fields and in native grasslands, and for response variables: growth in tiller number, final tiller number and shoot mass. *: $P<0.05 ; * *: P<0.01 ; P<0.001$. D.f. error $=555$.

\begin{tabular}{llllllll}
\hline & \multicolumn{3}{c}{ Old-fields } & \multicolumn{3}{c}{ Native grasslands } \\
\hline Source & d.f. & Growth & Number & Mass & Growth & Number & Mass \\
Population & 12 & $2.19^{*}$ & $1.80^{*}$ & 1.45 & 0.75 & 0.66 & 0.85 \\
Competition & 6 & $2.52^{*}$ & $2.30^{*}$ & $7.77 * * *$ & $3.88^{* *}$ & $4.88^{* * *}$ & $8.85^{* * *}$ \\
P x C & 12 & $2.59 * *$ & $2.34^{* *}$ & 1.59 & 0.57 & 0.84 & 0.88 \\
Site (S) & 6 & $5.47 * * *$ & $2.62^{*}$ & 1.66 & $2.35^{*}$ & $2.53^{*}$ & 1.57 \\
\hline
\end{tabular}


Invasion and selection - 28

Figure captions

Fig. 1. Each dot marks the location of a study site in Grasslands National Park, near Val Marie, Saskatchewan, Canada. Seeds of the invasive grass Agropyron cristatum were collected from three populations (seeded in an old field decades earlier, $50 \mathrm{~m}$ outside the seeded field in native grassland, and $100 \mathrm{~m}$ outside the seeded field) at each site, and transplanted into common gardens in both seeded fields and native grassland with and without neighbors at each site. Map data (C) 2016 Google.

Fig. 2. Mean ( \pm 1 s.e.) relative tiller growth ( $a$; (tiller number in August 2005 - tiller number in June 2004)/tiller number in June 2004), final number of tillers per transplant (b) and shoot mass (c) of transplants of the invasive grass Agropyron cristatum grown for two seasons in old fields. Transplants represented three populations (seeded: grown from seeds collected from seeded fields; $50 \mathrm{~m}$ : seeds collected $50 \mathrm{~m}$ outside the field in native grassland; $100 \mathrm{~m}$ : seeds collected $100 \mathrm{~m}$ outside the field in native grassland). Transplants were grown without (open bars) or with (shaded bars) neighbors. Means are averaged over six fields. $\mathrm{P}$ : significant $(P<0.05)$ population effect; $\mathrm{C}$ : significant competition effect; $\mathrm{P}^{*} \mathrm{C}$ : significant population $\mathrm{x}$ competition interaction (Table 1). a, b: means not sharing letters are significantly different among populations. *: means are significantly different between competition treatments.

Fig. 3. Mean ( \pm 1 s.e.) relative tiller growth ( $a$; (tiller number in August 2005 - tiller number in June 2004)/tiller number in June 2004), final number of tillers per transplant (b) and shoot mass (c) of transplants of the invasive grass Agropyron cristatum grown for two seasons in native grasslands. Transplants represented three populations (seeded: grown from seeds collected from seeded fields; $50 \mathrm{~m}$ : seeds collected 50 m outside the field in native grassland; $100 \mathrm{~m}$ : seeds 
collected $100 \mathrm{~m}$ outsi the field in native grassland). Transplants were grown without (open bars) or with (shaded bars) neighbors. Means are averaged over six grasslands. C: significant $(P<$ 0.05) competition effect (Table 1). 


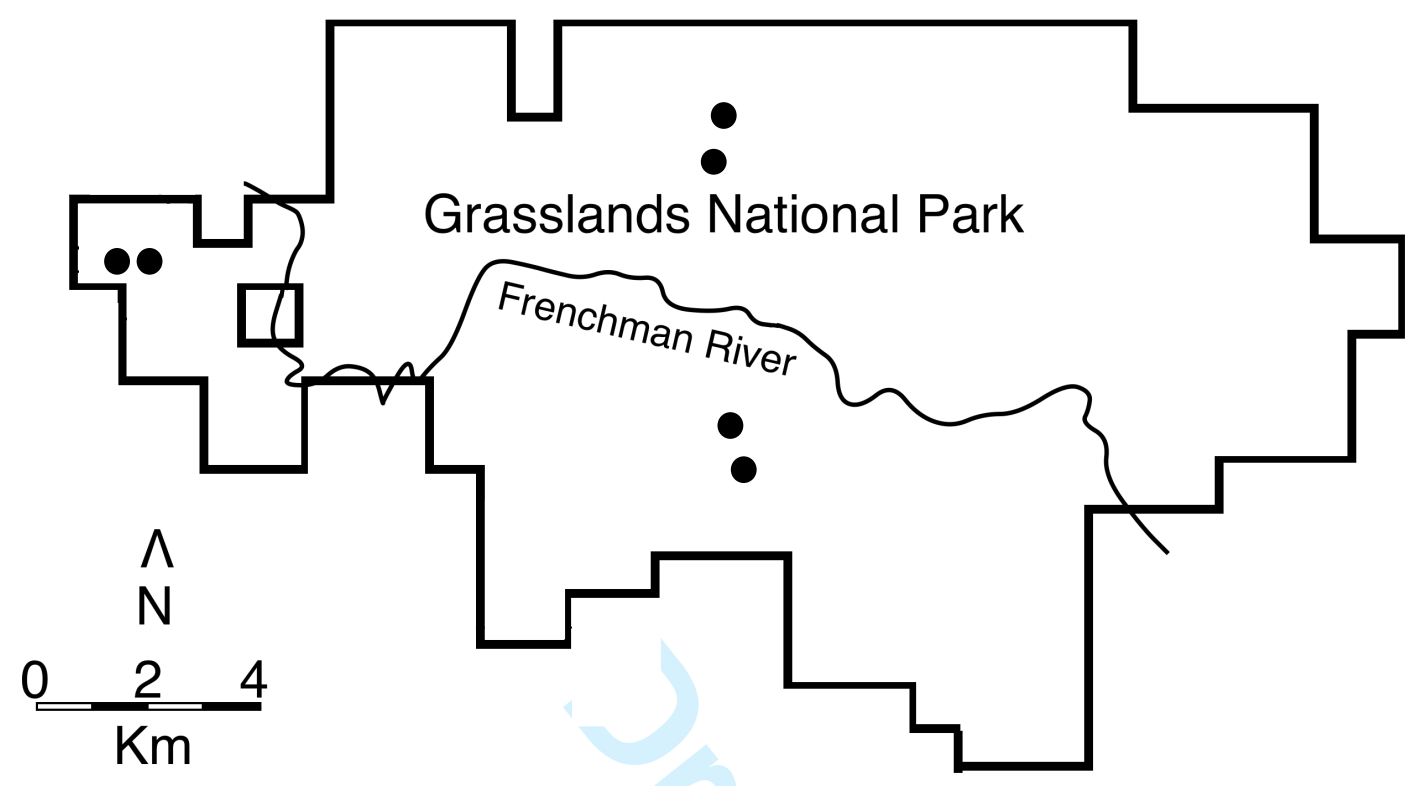




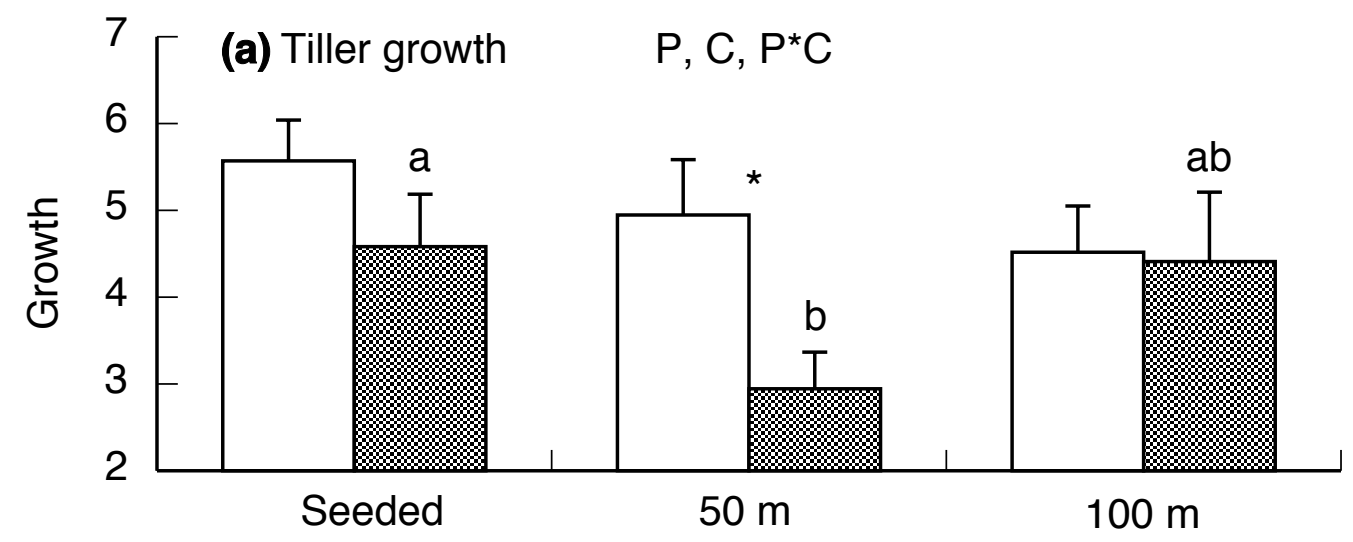

(b) Tiller number
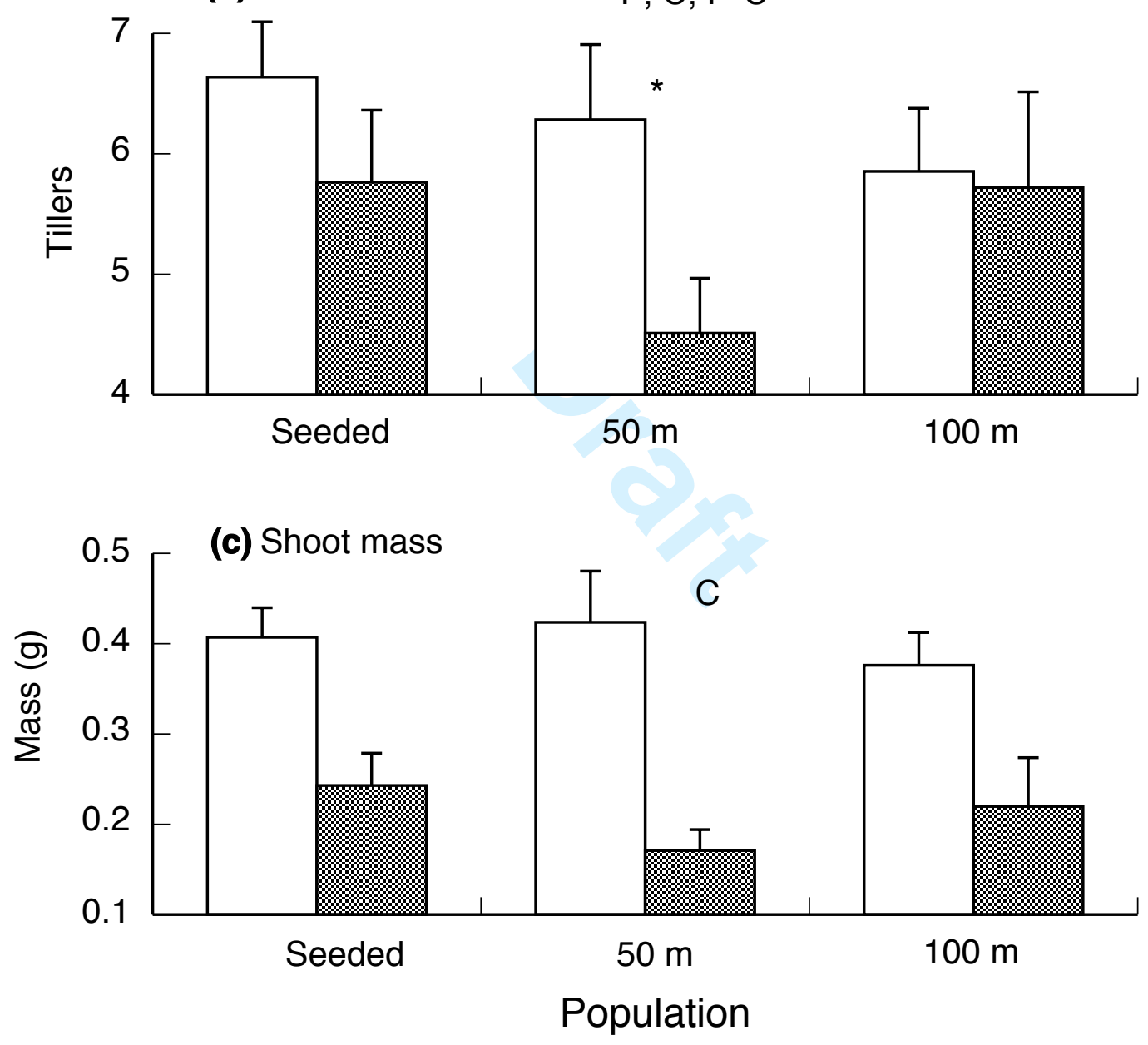

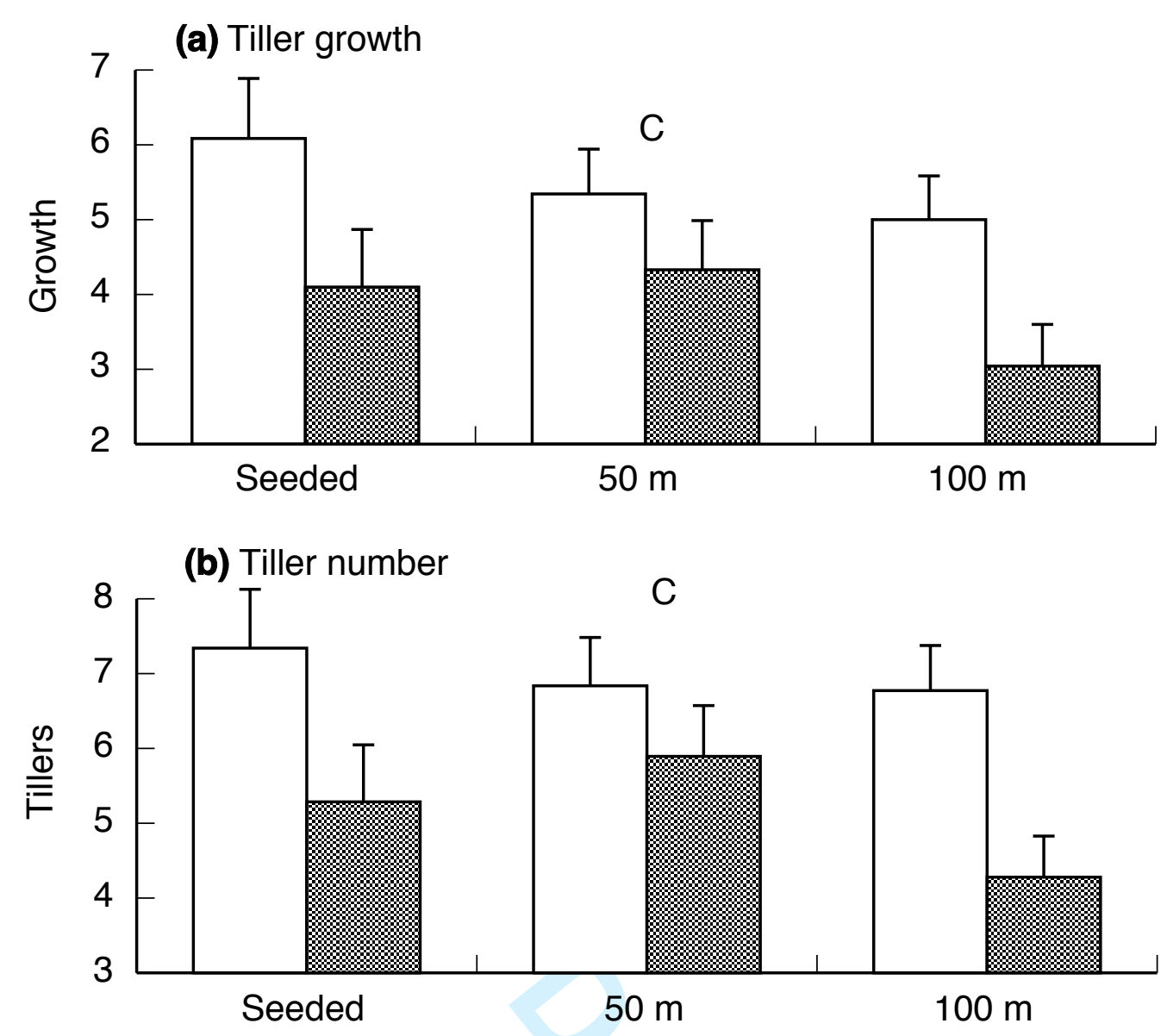

(c) Shoot mass

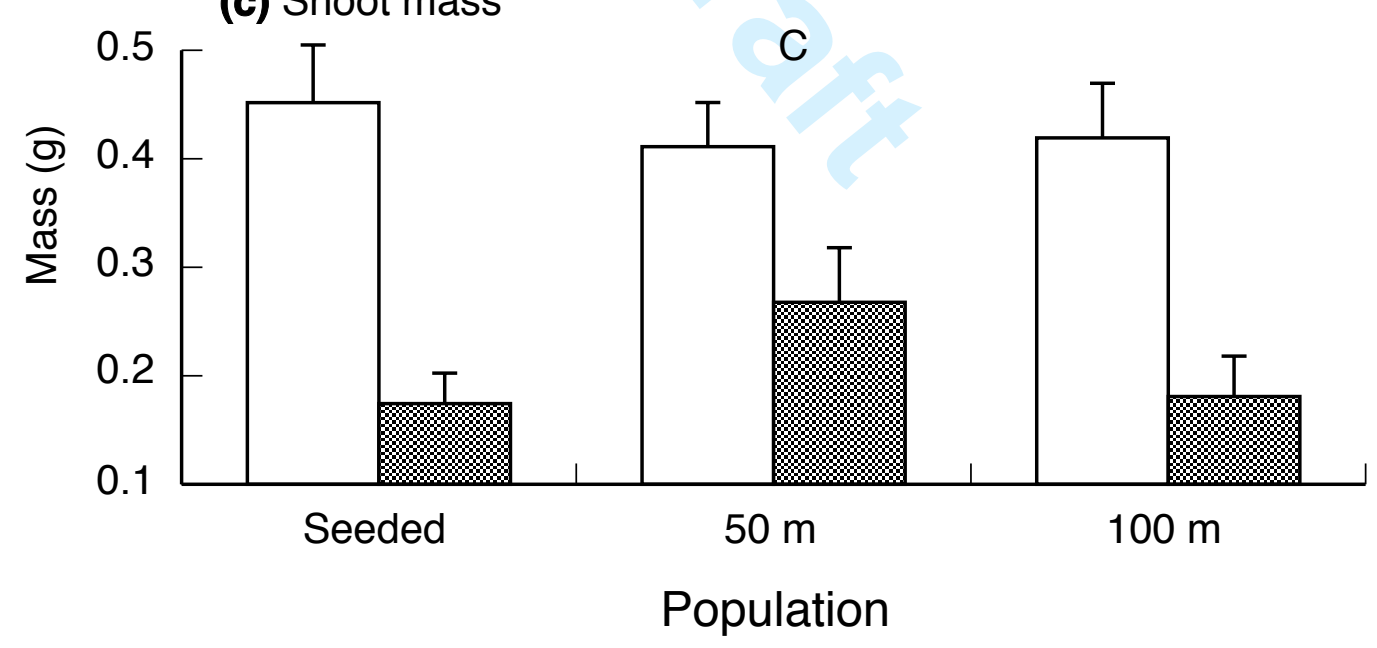

